\title{
As perspectivas de estudos sobre os sujeitos no PPGCI/UFMG
}

\author{
Carlos Alberto Ávila Araújo ${ }^{I}$ \\ http://orcid.org/0000-0003-0993-1912
}

\section{Adriana Bogliolo Sirihal Duarte ${ }^{I I}$}

Lígia Maria Moreira Dumont ${ }^{I I I}$

${ }^{I}$ Universidade Federal de Minas Gerais, Belo Horizonte, MG, Brasil.

Professor do PPGCI/UFMG. Doutor em Ciência da Informação pela UFMG.

II Universidade Federal de Minas Gerais, Belo Horizonte, MG, Brasil.

Professora do PPGCI/UFMG. Doutora em Ciência da Informação pela UFMG.

III Universidade Federal de Minas Gerais, Belo Horizonte, MG, Brasil.

Professora do PPGCI/UFMG. Doutora em Comunicação pela ECO-UFRJ/IBICT.

http://dx.doi.org/10.1590/1981-5344/3895

Apresenta a maneira como a temática do sujeito é pesquisada no âmbito da linha de pesquisa "Usuários, gestão do conhecimento e práticas informacionais" do Programa de Pós-Graduação em Ciência da Informação da Universidade Federal de Minas Gerais (PPGCI/UFMG). A temática é tratada a partir de três eixos: práticas informacionais, mediações e leitura, designando as três principais formas por meio das quais a temática vem sendo pesquisada. São apresentados os conceitos centrais e autores que as fundamentam, grupos de pesquisa e dissertações e teses defendidas por cada uma delas. Conclui-se que a especificidade da perspectiva delineada a partir desse conjunto de investigações representa uma contribuição singular para os estudos informacionais destacando o caráter ativo dos sujeitos, ou usuários da informação, a importância do contexto, e a vinculação dos processos informacionais com a constituição das identidades e da própria realidade social.

Palavras-chaves: Práticas informacionais. Mediações. Leitura. Sujeito informacional. Usuários da informação. 


\section{The perspectives of studies on subjects in PPGCI / UFMG}

This paper presents the way in which the topic of the subject is researched within the research line "Users, knowledge management and information practices" of the Postgraduate Program in Information Science of the Federal University of Minas Gerais (PPGCI / UFMG). The thematic is treated from three axes: information practices, mediations and reading, designating the three main ways through which the subject, or information users, has been researched. It presents the central concepts and authors that support them, research groups and dissertations and theses defended for each of them. It is concluded that the specificity of the perspective delineated from this set of investigations represents a unique contribution to the informational studies highlighting the active character of the subjects, the importance of the context, and the linking of informational processes with the constitution of identities and social reality.

Keywords: Information practices. Mediations. Reading. Informational subject. Information users.

Recebido em 12.03.2019 Aceito em 12.03.2019

\section{Introdução}

O Programa de Pós-Graduação em Ciência da Informação (PPGCI) da Universidade Federal de Minas Gerais (UFMG) tem essa denominação desde 1997. Até então, o que existia era o Mestrado em Biblioteconomia, criado em 1976, que passou a ser PPGCI com a criação do doutorado. $\mathrm{Na}$ ocasião, havia uma área de concentração - "Produção, organização e utilização da informação" - com três linhas de pesquisa: Informação e Sociedade (IS), Informação Gerencial e Tecnológica (IGT) e Tratamento da Informação e Bibliometria (TIB).

No PPGCI realizavam-se pesquisas sobre temas variados e com enfoques variados. Naturalmente, estudar os sujeitos, as pessoas se relacionando com informação, era algo presente em todas as dissertações e teses desenvolvidas, mas com perspectivas muito variadas. Na linha IS, havia uma preocupação muito grande com as classes sociais desfavorecidas economicamente e marginalizadas, o que teve como 
consequência um volume significativo de pesquisas voltadas para esse público, para denúncias de processos de dominação e exclusão pela via informacional, e para perspectivas informacionais de constituição da democracia e da cidadania. Na linha IGT foram realizados alguns estudos, sobretudo de perfis de gerentes e administradores, bem como dos recursos informacionais usados nos ambientes organizacionais. Na linha TIB não chegou a haver propriamente estudos com ênfase nos sujeitos, destacando-se pesquisas sobre instrumentos de organização da informação e abordagens bibliométricas.

Em 2003 o PPGCI passou por uma reformulação e os nomes das linhas foram alterados. A linha TIB passou a chamar-se "Organização e uso da informação". Com a palavra "uso", passou a contemplar estudos sobre uso da informação, o que significou mapeamentos, sobretudo de cientistas, sobre as fontes de informação mais utilizadas por eles e aspectos descritivos dessa utilização. A linha IGT mudou seu nome para "Gestão da informação e do conhecimento". Nela, foram realizadas diversas pesquisas sobre comportamento informacional dentro das organizações e empresas, numa linha cognitiva buscando identificar conhecimentos tácitos e explícitos e mapear uso de instrumentos de gestão de ambos. E a linha IS passou a chamar-se "Informação, sociedade e cultura". Os estudos numa perspectiva macrossocial, ancorados principalmente numa perspectiva marxista, continuaram a ser realizados, somando-se a eles, com a integração da palavra "cultura", também estudos sobre os sujeitos envolvendo uma mirada mais antropológica.

Novamente em 2016 o PPGCI passou por reformulação, desta vez ainda mais profunda, envolvendo inclusive alteração na área de concentração, que passou a ser "Informação, mediações e cultura", numa clara redefinição sobre o próprio significado do fenômeno informacional, das maneiras de estudá-lo e mesmo do sentido da atividade científica e seu papel na sociedade. Contribuiu também, sobremaneira, a criação dos novos cursos de graduação na Escola de Ciência da Informação da UFMG, o curso de arquivologia e o curso de museologia. Até então, existia apenas o curso de biblioteconomia, com o qual o PPGCI sempre estabeleceu um diálogo importantíssimo. Mas havia o interesse em construir fundamentos de diálogo com as três formações em nível de graduação então ofertadas, e esse foi, na verdade, o fator fundamental da alteração.

As linhas de pesquisa anteriores foram dissolvidas e surgiram outras três linhas. A primeira se chama "Memória social, patrimônio e produção do conhecimento" e tem por ementa "Distingue-se por dar ênfase aos aspectos construídos coletivamente, na sedimentação promovida pela memória social, naquilo que será tido como herança (patrimônio) de dada coletividade, num campo de relações desiguais de acesso e produção, considerando ainda as dimensões da cultura informacional, os impactos sociais e a viabilidade tecnológica de produtos e serviços de informação". A segunda se chama "Políticas públicas e organização da informação" e tem a seguinte ementa: "Define-se pela ênfase nos aspectos institucionais relacionados com os ciclos de políticas públicas arquivísticas e 
informacionais, além dos aspectos de intervenção técnica sobre os documentos e a informação (gestão, tratamento, indexação, catalogação, inventário) compreendidos como produto cultural humano". Por fim, a terceira denomina-se "Usuários, gestão do conhecimento e práticas informacionais" e sua ementa é "Ênfase no caráter ativo dos sujeitos no uso dos recursos informacionais, suas apropriações, interpretações, diferentes usos, compartilhamentos, resistências, em aspectos e ambientes distintos tais como os contextos de eficácia e eficiência gerenciais envolvidos com esses recursos informacionais e seus usos, com o desafio de promover sua gestão (de forma a subsidiar as decisões organizacionais) ou os contextos educacionais e de pesquisa".

A primeira linha, como descrito, se foca em questões macrossociais, relacionadas com memória, patrimônio, técnicas e tecnologias, enquanto a segunda está diretamente envolvida com a dimensão estratégica da formulação de políticas, serviços e instrumentos de informação. $\mathrm{Na}$ terceira linha há uma ênfase, por um lado, na dimensão de gestão; e uma outra, definida pelos termos "usuários" e "práticas", propriamente focada nos sujeitos. Assim, tanto na primeira quanto na segunda linhas, e também na parte gerencial da terceira, há claro uma consideração dos sujeitos, das pessoas que produzem, fazem circular, usam e se apropriam da informação. Mas é na "segunda parte", por assim dizer, da terceira linha de pesquisa, que há propriamente uma centralidade dos sujeitos, com a consideração de seu caráter ativo, protagonista, como lugar de problematização (formulação das perguntas de pesquisa) e de demonstração (realização das pesquisas e busca por respostas) no âmbito do PPGCI.

Esse pequeno histórico foi necessário porque o objetivo deste texto é, justamente, apresentar como, no PPGCI atual, está sendo contemplada a questão dos sujeitos (isto é, das pessoas, ou dos usuários, sendo que cada termo também possui um certo histórico no campo da ciência da informação). Para isso, é importante num primeiro momento demonstrar como se deram as diferentes maneiras de abordá-lo e estudá-lo no PPGCI. Atualmente, essa centralidade, como visto, se encontra em uma parte da linha "Usuários, gestão e práticas informacionais" e vem sendo desenvolvida nas pesquisas de mestrado e doutorado, além, claro, das pesquisas dos professores que compõem o programa, basicamente em torno de três grandes temáticas: práticas informacionais; mediações; leitura. A seguir, são apresentadas as três e, ao final, faz-se uma análise sobre o significado destes estudos no âmbito da ciência da informação em geral e do PPGCI em especial.

\section{Práticas informacionais}

O conceito de práticas informacionais surgiu no âmbito das pesquisas sobre "usuários da informação", uma área que vivenciou, em sua história, pelo menos dois grandes modelos de estudo. O primeiro, normalmente identificado como "estudos de uso", consistiu num vasto conjunto de investigações empíricas sobre o acesso físico das pessoas a 
itens e serviços informacionais, sobre a caraterização desse uso (por frequência, por partes ou setores, por urgência, por grau de satisfação) e sobre sua decomposição por aspectos sociodemográficos dos usuários (por atributos "objetivos" tais como sexo, idade, profissão, renda, escolaridade, entre outros). A base conceitual se situou entre as noções de demanda, desejo, necessidade, uso e requisito, de um lado, e de fontes, serviços, sistemas e unidades de informação, de outro (LINE, 1974). Reunindo todas essas questões, e subjacente a elas, encontra-se a inspiração fundamental desta abordagem: o positivismo - isto é, a aplicação dos mesmos métodos das ciências naturais (exatas e biológicas) aos fenômenos humanos e sociais. Como consequência de sua aplicação nos estudos de usuários, verificou-se uma preocupação, central, com o estabelecimento de leis do comportamento do usuário da informação, como, por exemplo, o princípio do menor esforço. O objetivo destas leis é estabelecer padrões de comportamentos invariáveis, isto é, válidos para diferentes contextos, em diferentes locais e épocas. Além disso, tais estudos procuraram "medir" o comportamento dos usuários. O usuário, nessa perspectiva, é quase que completamente destituído da condição de "sujeito", assemelhando-se a um "processador de dados". Isso porque é entendido em termos de um "portador" de uma demanda (entendida, esta, como a ausência de um dado específico) e a sua satisfação como a entrega de um item documental a satisfazer essa demanda.

O segundo consiste na chamada abordagem cognitiva e desenvolveuse por meio do conceito de comportamento informacional e de diversos modelos que buscaram ver as etapas existentes e os fatores intervenientes entre a manifestação da necessidade de informação e o uso (DERVIN; NILAN, 1986). Entre as etapas pode-se citar a seleção, exploração, coleta, diferenciação, extração e verificação; e entre os fatores, características emocionais, cognitivas, fisiológicas, ambiente de trabalho, ambiente cultural, entre outros. A base conceitual se situa, neste caso, em torno da noção de processo entre a necessidade e o uso, passando pela busca, e de uma dimensão cognitiva que determina todo o processo. Note-se que, embora se apresentassem como proposta de superar as limitações do modelo anterior (vinculado apenas ao uso), os modelos cognitivos reproduziram a lógica binária necessidade/busca, como uma aplicação do mecanismo estímulo-resposta da psicologia comportamental. Seu incremento foi o interesse em decompor as etapas que marcam esse processo de forma a ver o papel do sucesso e do fracasso, ou da demanda a tal tipo ou a tal tipo de recurso, como elementos intervenientes do processo. O usuário continuou sendo compreendido numa lógica mecanicista, um ser que sofre os efeitos de forças externas que atuam sobre ele ou, então, é apenas um ser "cognoscente", isto é, um ser que acumula dados sobre a realidade externa e que, de tempos em tempos, conforme sente uma "lacuna" nesses dados, recorre a sistemas de informação para resolver a "anomalia".

Como uma alternativa ao caráter restritivo e "asfixiante" tanto dos estudos de uso da informação como daqueles sobre o comportamento informacional (um indivíduo que, a partir de um estímulo externo, procura 
um sistema de informação para satisfazer sua necessidade de informação), alguns pesquisadores do campo de estudos de usuários da informação propuseram o conceito de "prática informacional", retomando a ideia de práxis como todo "[...] modo de agir no qual o agente, sua ação e o produto de sua ação são termos intrinsecamente ligados e dependentes uns dos outros, não sendo possível separá-los" (CHAUÍ, 1984, p. 20). Um marco importante para a visibilidade do surgimento dessa abordagem no cenário internacional é a realização do primeiro encontro internacional de investigadores da área, realizado na cidade de Tampere, na Finlândia, em 1996. À época, o evento foi denominado Information Seeking in Context, e a importância do contexto nos processos de busca da informação foi ressaltada não somente no nome do evento, mas nas várias apresentações e debates que ali ocorreram. Enfocar o contexto significa que a análise muda do cognitivo para o social e que, portanto, passa-se a considerar tanto as formas como o contexto interfere nas ações do indivíduo quanto como as ações do indivíduo são passíveis de alterar o contexto, num ciclo constante. Uma consequência disto é a adoção da terminologia práticas informacionais para denominar os estudos conduzidos a fim de investigar como se dão os interrelacionamentos entre o sujeito e a informação. Savolainen (2007) apresenta uma revisão histórica que justifica a adoção do termo. Segundo o autor, uma escolha terminológica e movimento discursivo significativos ocorrem a partir da divulgação da pesquisa de Pamela McKenzie (2003), que defende que a terminologia "práticas informacionais" é mais adequada que "busca de informação" ou "comportamento informacional", uma vez que abrange toda a gama de atividades presentes nas diferentes situações e contextos apresentados. No entanto, McKenzie não é a única a propor a adoção do termo. O conceito de práticas informacionais também é elaborado por Talja e Hansen (2005). Eles enfatizam que as práticas informacionais estão firmemente inseridas no trabalho e em outras práticas sociais e que elas se baseiam na prática social de uma comunidade de praticantes, em uma infraestrutura sociotécnica e em uma linguagem comum. Talja e Hansen assumem que

a busca e recuperação de informações são dimensões das práticas sociais e que são instâncias e dimensões de nossa participação no mundo social em diversos papéis e em diversas comunidades de partilha. Receber, interpretar e indexar informações ... fazem parte da rotina de realização das tarefas de trabalho e da vida cotidiana (TALJA; HANSEN, 2005, p. 125, tradução nossa). Igualmente Lloyd (2009) defende uma abordagem praxiológica para os estudos de usuários, por meio da utilização na noção de ontologias contextuais de Schatzki aliada a referenciais de Giddens e Bourdieu. Araújo (2017), enfatiza: O conceito de "prática", tomado da Etnometodologia, se deu com o objetivo de ver em que medida os "fatos sociais" são constantemente produzidos pelos indivíduos. Não existe, nesta perspectiva, um mundo de regras, normas e estruturas exterior e independente das interações. Tem-se aqui a ideia de processo: o ato dos sujeitos de continuamente atualizarem as regras e modelos por meio de suas ações. 
Portanto, a adoção da terminologia práticas informacionais e da postura sociocultural para empreender estudos daquele que passamos a denominar não mais usuário da informação e sim sujeito informacional (ressaltando desse modo seu caráter de ator) é consistente com o momento histórico da valorização do contexto nas investigações, considerando as relações dialógicas entre sujeito e contexto. "O contexto é considerado como um elemento constitutivo das ações dos sujeitos e, ao mesmo tempo, por elas constituído a partir de uma relação dialógica. 0 individual e o social também são considerados como interdependentes" (ROCHA; SIRIHAL DUARTE; PAULA, 2017, p. 39).

Do ponto de vista de sua fundamentação, a ideia de práticas pode ser compreendida a partir de um quadro proposto por Bourdieu (1996), que distingue três modos por meio dos quais foram construídos os conhecimentos científicos sobre a realidade humana e social. O primeiro deles, apontado pelo autor, é o fenomenológico (representado pelo interacionismo simbólico e pela etnometodologia) que analisa as maneiras como o mundo é visto, pelos sujeitos, como algo natural, óbvio, evidente - e que ficaria, portanto, num nível subjetivo. O segundo é o objetivista, no qual se encontram o marxismo e o estruturalismo, que analisa as relações objetivas que estruturam as práticas, de forma independente das consciências individuais. Tal abordagem negligenciaria o ponto de vista subjetivo dos agentes.

$\mathrm{Na}$ tentativa de superar as limitações de ambas tendências, Bourdieu (1996) propõe o que ele denomina abordagem "praxiológica", que reposiciona o pesquisador, que passa ter como objeto de estudo o sistema de relações objetivas e também o processo de interiorização desse sistema sob a forma de disposições para a ação. Encontra-se aqui, por meio da expressão "praxiológica", a ideia de "práxis", isto é, o movimento mesmo por meio do qual os sujeitos agem no mundo e, como causa e também consequência dessa ação, constroem esse mesmo mundo. Essa é a ideia básica que fundamenta o conceito de "práticas" presente na expressão "práticas informacionais".

O raciocínio que conduz essa ideia busca realizar uma crítica tanto ao subjetivismo quanto ao objetivismo no entendimento da ação humana. O subjetivismo pressupõe que a ação humana é sempre um produto da vontade de um sujeito consciente e capaz de se projetar no futuro, antecipando as consequências de suas ações. A ação então é resultado de projetos, preferências, escolhas, intenções e cálculos realizados por um indivíduo, portanto algo que pode ser explicado em termos individuais, o que significa também atribuir uma grande autonomia aos sujeitos. Na outra ponta, o objetivismo enxerga os atores como suportes mecânicos das estruturas, como que movidos de maneira inconsciente - suas ações compreendidas como simples execução de regras sociais, aplicação de significados dados externamente.

Como forma de superar tal dicotomia, e portanto desenvolver sua perspectiva praxiológica, Bourdieu desenvolve o conceito de habitus, que "fornece, ao mesmo tempo, um princípio de sociação e de individuação: sociação porque as nossas categorias de juízo e de ação, vindas da 
sociedade, são partilhadas por todos aqueles que foram submetidos a condições e condicionamentos sociais similares (assim podemos falar de um habitus masculino, de um habitus nacional, de um habitus burguês, etc.); individuação porque cada pessoa, ao ter uma trajetória e uma localização únicas no mundo, internaliza uma combinação incomparável de esquemas" (WACQUANT, 2017, p. 215).

Trata-se de um tipo de movimento intelectual marcado pelo pensamento relacional (tal como formulado por Cassirer), isto é, que busca sempre o "entre", o movimento incessante entre o estruturado e o estruturante. É nesse sentido que estudar as práticas informacionais constitui-se num movimento constante de capturar as disposições sociais, coletivas (os significados socialmente partilhados do que é informação, do que é sentir necessidade de informação, de quais são as fontes ou recursos adequados) e também as elaborações e perspectivas individuais de como se relacionar com a informação (a aceitação ou não das regras sociais, a negociação das necessidades de informação, o reconhecimento de uma ou outra fonte de informação como legítima, correta, atual), num permanente tensionamento entre as duas dimensões, percebendo como uma constitui a outra e vice-versa.

Na abordagem pelo conceito de práticas informacionais há, pois, uma progressiva aproximação ao que é propriamente humano nos usuários da informação: a sua capacidade imaginativa, criadora, na apropriação da informação; e a dimensão coletiva do seu "existir", constituidora de todos os seus atos, entre os quais aqueles ligados à informação (ARAúJO, 2012). Trata-se de uma perspectiva que busca conjugar uma perspectiva microscópica de análise, originária da fenomenologia, com uma aproximação compreensiva, em busca dos significados, vinda da tradição hermenêutica, com ênfase no caráter coletivo e intersubjetivo das ações promovidas pelos sujeitos informacionais, bem como no enraizamento destas ações em contextos sócio-históricos específicos (ARAÚJO, 2017).

No âmbito do PPGCI, merece destaque a criação de um grupo de pesquisa voltado para os estudos de usuários da informação, mas com uma proposta de trabalhar e desenvolver o conceito: trata-se do grupo EPIC, Estudos em Práticas Informacionais e Cultura, composto por pesquisadores brasileiros (Adriana Bogliolo Sirihal Duarte, Carlos Alberto Ávila Araújo, Cláudio Paixão Anastácio de Paula e Eliane Cristina de Freitas Rocha), do Uruguai (Martha Sabelli), da Espanha (Aurora González-Teruel), da Argentina (Silvia Albornoz) e da Colômbia (Edilma Naranjo Vélez). Embora - grupo de pesquisas tenha sido oficialmente criado e cadastrado no Conselho Nacional de Desenvolvimento Científico e Tecnológico (CNPq) em 2014, desde muito antes seus integrantes vêm desenvolvendo trabalhos conjuntos e caminhando para a construção de uma perspectiva sociocultural de estudos de usuários, convergindo finalmente para a ideia de "práticas informacionais" em sua associação ao conceito de "cultura". O grupo não realizou ainda uma pesquisa unificada, mas vem se construindo a partir de debates, intercâmbios e da realização de pesquisas com distintas realidades empíricas na forma de investigações de mestrado e doutorado, além de uma preocupação com o ensino da disciplina usuários 
da informação no âmbito da graduação e da pós-graduação (SIRIHAL DUARTE; ARAÚJO; PAULA, 2017).

As pesquisas do grupo têm tido, como objetos de pesquisa, realidades empíricas distintas daquelas típicas dos estudos de usuários tradicionais (cientistas, empresários, governo), tais como grupos sociais pertencentes a minorias ou pertencentes a um contexto referente ao cotidiano. Isso não significa que o grupo abdique de investigar papéis sociais referentes a práticas informacionais no campo profissional ou científico, apenas isso ocorre com menor frequência. Entre as dissertações e teses defendidas no âmbito do EPIC podem ser mencionadas as que estudaram as práticas informacionais das profissionais do sexo da zona boêmia de Belo Horizonte (SILVA, 2008), de ouvintes assíduos de rádio (PESSOA, 2010), de idosos em sua experiência da inclusão digital (GANDRA, 2012), de professores em sua organização político-sindical (PINTO, 2012), de pessoas com cegueira congênita e adquirida em interação com a Web (ROCHA, 2013), de bibliotecários durante a atividade de indexação em bibliotecas universitárias (ARAUJO, 2013), de usuários de um sistema de extensão da UFMG (TERTO, 2013), de nativos digitais usando a biblioteca escolar e a ferramenta de busca Google (ANTUNES, 2015), de docentes e discentes de um programa de pós-graduação stricto sensu na relação de orientação estabelecida entre eles (COELHO DE SÁ, 2015), de mães de crianças com alergias alimentares (BARROS, 2016) e de clientes de serviços de estética (VASCONCELOS, 2016).

\section{Mediações}

Almeida Júnior conceitua mediação, no âmbito da ciência da informação, como toda ação de interferência - realizada pelo profissional da informação -, direta ou indireta; consciente ou inconsciente; singular ou plural; individual ou coletiva; que propicia a apropriação de informação que satisfaça, plena ou parcialmente, uma necessidade informacional (ALMEIDA JÚNIOR, 2009, p. 92).

Para o autor, a mediação da informação pode ser tanto explícita quanto implícita. Na mediação explícita, fica clara a interação entre o profissional da informação e o usuário da informação. São exemplos disso atividades como a contação de histórias ou a entrevista de referência no espaço da biblioteca; a visita guiada ou as ações educativas no espaço do museu; a localização e disponibilização de documentos no espaço do arquivo. Mas para que a mediação explícita possa ocorrer com sucesso, um processo prévio de mediação implícita, também realizado por profissionais da informação, tem de ter sido realizado. Trata-se da organização da informação, através de atividades como sua classificação, indexação, enfim, de todo o tratamento necessário para que ela possa ser localizada, seja através do mediador explícito, seja de modo autônomo pelo sujeito que dela necessita.

Percebe-se, portanto, que quanto maior o volume de informação, maior a necessidade do mediador, seja para atuar de modo implícito, em 
sua organização, garantindo seu acesso futuro, seja para atuar de modo explícito, interferindo no encontro do sujeito com a informação. Almeida Júnior (2007) ainda ressalta que a interferência do profissional da informação, quer seja implícita ou explícita, deve ser feita de modo cuidadoso e responsável, atentando para que seus próprios valores e princípios pessoais não interfiram na formação do conhecimento do outro, de modo que ele, profissional da informação, evite que sua interferência se confunda com manipulação, já que os limites entre uma coisa e outra são um tanto tênues.

Dentre os diferentes tipos de bibliotecas - públicas, escolares, comunitárias, universitárias, especializadas, etc. - uma em que o papel do mediador se faz fundamental é a biblioteca escolar. É nesse ambiente que se forma o leitor e se educa para a competência informacional (capacidade de se reconhecer a necessidade de informação, saber como buscá-la, localizá-la e utilizá-la de modo crítico), atividades em que a presença da mediação explícita se torna condição sine qua non para o sucesso. Nesse sentido, O Grupo de Estudos em Biblioteca Escolar (GEBE), que este ano completa 20 anos, integra pesquisadores e estudantes em torno de atividades de ensino, pesquisa e extensão relacionadas especialmente a questões sobre a função educativa da biblioteca, procurando uma melhor compreensão do potencial dessa instituição como espaço de ação pedagógica. Entre as dissertações e teses defendidas no âmbito do GEBE e relacionadas com a temática mediações podem ser mencionadas as que estudaram a colaboração no contexto da função educativa do bibliotecário (PEREIRA, 2016); o papel do bibliotecário como mediador na formação de leitores (MOREIRA, 2014); a influência da cultura escolar nas práticas educativas em bibliotecas escolares (FÉLIX, 2014); os processos de busca de informação e o comportamento informacional dos nativos digitais, bem como sua relação e expectativas com a biblioteca e o bibliotecário (ANTUNES, 2015; PAIVA, 2018). Além de orientar pesquisas de mestrado e doutorado, os integrantes do GEBE desenvolvem suas próprias pesquisas, que resultam em publicações nacionais e internacionais, através de artigos e livros, além de participarem anualmente do principal evento internacional que investiga a biblioteconomia escolar, o congresso da International Association of School Librarianship (IASL). Toda a produção dos integrantes do GEBE encontram-se divulgadas no site do grupo ${ }^{1}$, que disponibiliza, também, uma base de dados que reúne referências de documentos sobre biblioteca escolar produzidos no Brasil a partir da década de 1960. Inclui livros, artigos de periódicos, dissertações, teses, trabalhos apresentados em eventos e documentos governamentais. Não são incluídos monografias de especialização e trabalhos de conclusão de curso.

Além da questão da biblioteca escolar, o conceito de mediações também vem sendo estudado, dentro da perspectiva de foco na ação dos

${ }^{1}$ Disponível em: <http://gebe.eci.ufmg.br>. Acesso em: 24 nov. 2018. 
sujeitos, em relação a outros tipos de biblioteca ou outras dimensões da ação bibliotecária - como, por exemplo, a análise de como bibliotecários realizam a atividade de indexação (ALONSO, 2012) ou como os bibliotecários desenvolvem estudos de usuários em suas bibliotecas de atuação (SEPÚLVEDA, 2012). Também se destacam estudos ligados ao campo da arquivologia, com pesquisa sobre estudos de usuários na área (VAZ, 2015) e no campo da museologia, com estudo de visitantes de museus (GRANDRA, 2017), além de trabalho sobre a questão do sujeito na arquivologia, na biblioteconomia e na museologia (ARAÚJO, 2013).

\section{Leitura}

A linha de pesquisa "Usuários, gestão do conhecimento e práticas informacionais" possui também uma vertente de estudos voltada à obtenção de informações e a introjeção de conhecimentos por intermédio de diversificadas formas de leitura. Instiga particularmente os pesquisadores do grupo de pesquisa Informação e Leitura o gosto pela leitura de lazer como romances populares, revistas em quadrinhos, dentre outras. Analisa, também, através do estudo dos usuários dessas leituras, o desenvolvimento de competências informacionais, com destaque ao segmento de leitores agregados a comunidades marginalizadas, ou mesmo excluídas, que sobrevivem em constante mutação e apresentam características instáveis e complexas. O enfoque de estudo centraliza-se nas maneiras pelas quais o leitor, em determinados eventos, revoca de seu cognóscio informações e sugestões de ações adquiridas através da leitura, para usá-las em contexto similar real. Entende-se que o caráter contextual de ações aparentemente corriqueiras que podem ser processadas, avaliadas e eventualmente reutilizadas.

No intuito de apresentar algumas reflexões que possam auxiliar na elaboração de futuras pesquisas sobre leitura como uma forma de explorar possibilidades de mudanças na vida cotidiana de indivíduos e grupos, outra temática do grupo de pesquisa Informação e Leitura é a discussão das escolhas teórico-metodológicas passíveis de aplicação em pesquisas sobre leitores e leituras. Em destaque o método fenomenológico e as orientações etnometodológicas, como uma das possibilidades para subsidiar o percurso metodológico de pesquisas dessa temática. Especial atenção é dada à observação participante, a entrevista - no caso de crianças apoiada na escuta sensível e nos desenhos comentados (DUMONT; PINHEIRO, 2015) - e a história de vida tópica. Dentre os diversos procedimentos metodológicos passíveis de aplicáveis, a etnometodologia constitui-se como fonte bastante adequada à coleta de dados. A abertura de diálogo entre a etnometodologia e a ciência da informação visa contribuir a uma abordagem de pesquisa válida para o estudo qualitativo em pesquisas que se reportam aos procedimentos implementados pelo senso comum na representação corrente do mundo e da ação. A relevância da etnometodologia na ciência da informação tornase especialmente apropriada, quando se lida com o usuário e o seu mundo de vida, suas experiências e a sua visão particular, diante das 
possibilidades de se reconstituir, a partir da informação e do conhecimento adquiridos pela leitura, necessidades para estabelecer a vivência entre pessoas e grupos. A etnometodologia, ainda, oferece novas formas de articulação com a leitura, visto que seu postulado investiga as propriedades racionais de expressões de indexação e outras ações práticas sociais contínuas e organizadas na vida cotidiana.

Outro enfoque de pesquisa já realizado pelo grupo de pesquisa Informação e Leitura foi a análise de cartas de leitores de jornais impressos da grande mídia (ESPÍRITO SANTO, 2012). Ao considerar os meios de comunicação mediadores de informações, além de produtores e reprodutores de padrões culturais e sociais, a pesquisa procurou identificar o que leitores escrevem aos jornais e como problematizam as temáticas abordadas em suas páginas; se haveria diferenças nos argumentos utilizados por cada gênero; e que argumentos utilizam para chamar a atenção dos editores e de seus futuros leitores. Para tanto, cartas enviadas em caráter espontâneo por e-mail ao jornal Estado de Minas foram analisadas no período de 30 de um mês e separou-se o material por temáticas. Foi feita a análise do discurso das cartas na íntegra, o que tornou possível conhecer a que valores recorrem leitores e leitoras, sobre quais hierarquias fundam os valores e em que lugares situam suas argumentações. Os resultados permitiram concluir que os homens assinam quase $80 \%$ das cartas enviadas ao jornal, porém os valores, hierarquias e lugares apresentados nas cartas de ambos os sexos reproduzem a formação ideológica e discursiva de cada indivíduo, muito mais que denunciam a que gênero pertence. Os dados permitem concluir que a mulher, quase a metade do público leitor dos grandes jornais brasileiros, os lê principalmente em busca de informação sobre diversos temas, em especial a política, acontecimentos locais, cultura e temas tidos como específicos do mundo feminino, como moda e família. Ela utiliza as informações para formar sua opinião e para interagir socialmente; porém prefere silenciar quando o assunto é publicar sua visão dos fatos e acontecimentos, provavelmente movida pelo status quo do feminino, que a mantém como sujeito coadjuvante do homem, inclusive nas páginas dos jornais.

Analisar as histórias em quadrinhos de super-heróis e seu público leitor é outro interesse do grupo de pesquisa Informação e Leitura (RAMOS, 2017). São observadas as experiências de leitores brasileiros quanto às variadas informações veiculas nas revistas e as concepções desses quadrinhos, identificando os contextos, sentidos e motivações que levam o leitor a prosseguir com essa leitura, inclusive durante sua vida como adultos. Para tanto, se recorre a articulações entre estudiosos e teorias que fornecem condições para proceder as investigações e a apropriação do conhecimento adquirido por meio dessa leitura, advindos principalmente da área da antropologia e da sociologia. Destacam-se: a etnometodologia, que permite contemplar o senso comum e as referências de sentido e significado estabelecidas pelo leitor; o estudo cultural que permite o acesso a elementos que influenciam o leitor dentro do seu contexto social; os eventos performáticos da antropologia, no caso 
entendidos como o ato de ler, pelo viés não somente do entretenimento, mas também da eficácia, a qual é capaz de gerar significativas repercussões junto a um ou mais indivíduos diante da leitura e da interpretação da ficcionalização, graças à sua capacidade de reelaborar a leitura através de reflexões estabelecidas sobre acontecimentos ocorridos em sua própria vida.

Mais recentemente, o grupo de pesquisa Informação e Leitura ampliou o foco das suas investigações, correlacionando a questão da leitura com as da competência em informação (DUMONT, 2017). Na busca de maior compreensão sobre a leitura científica e o desenvolvimento de competências em informação, relacionadas à leitura de textos científicos no contexto das bibliotecas universitárias no Brasil foi investigada a contribuição das ações e/ou atividades de educação de usuários presenciais e/ou online, promovidas pelas bibliotecas universitárias brasileiras vinculadas às instituições federais de ensino superior. 0 principal objetivo foi identificar o processo de formação de competências em informação dos estudantes/usuários, visando à construção de sujeitos autônomos e conscientes na condução do processo de busca e uso da informação (GOMES, 2016). A pesquisa se justificou por sua inserção nas abordagens conceituais da Biblioteconomia e da ciência da informação, pois pesquisar a temática educação de usuários e leitura em bibliotecas universitárias na perspectiva da construção para a competência em informação é investigar as inter-relações de acesso, uso e necessidades de informação associadas ao estudante/usuário na sociedade. Conclui-se que a educação de usuários e a leitura desenvolvida no âmbito das bibliotecas universitárias, necessita de uma nova (re)significação para contribuir com a competência em informação dos estudantes dos cursos de graduação presenciais.

Os estudos sobre leitura e competência informacional sob a ótica da ciência da informação possuem diversas aderências e proximidades. Tal constatação se baseia no princípio de que para ser capaz de adquirir a competência informacional, o leitor necessita desenvolver quase que paralela e paulatinamente as duas habilidades, que vão dando suporte e sustentação à sua proficiência. A pesquisa iniciou revisitando alguns autores que deram aporte às duas áreas, tanto no cenário nacional como o internacional. Continua investigando e destacando as interseções encontradas entre as duas áreas, relativas a temas como contexto, motivação e sentido. Mais uma vez na história da comunicação e da leitura acredita-se que as novas tecnologias de comunicação não modificaram as teorias sobre estes fenômenos, apenas surgiu mais um novo suporte da informação. A leitura prossegue sendo a principal forma de se obter informação e, portanto, as formas de desenvolver a competência em informação também apresentam poucas variações, surgindo as necessárias ao desenvolvimento de ações e habilidades específicas para buscar e acessar a informação em meio digital. Certamente o que se tem observado é a preocupação com os avanços e o aprofundamento dos estudos, principalmente na área de ciência da informação. 


\section{Conclusão}

Com as mudanças realizadas em 2016, o PPGCI estreitou seu vínculo com as áreas de arquivologia e museologia, mantendo o vínculo sempre existente com a biblioteconomia e fazendo desse movimento de vinculações a própria essência do tipo de ciência da informação produzida, pesquisada e ensinada. Nesse sentido, as linhas de pesquisa também se direcionaram para esse objetivo, o que ocorreu, também com a linha "Usuários, gestão do conhecimento e práticas informacionais" e, dentro dela, no âmbito dos estudos sobre os sujeitos, nas três perspectivas aqui apresentadas: práticas informacionais, mediações e leitura. Deve-se ressaltar que o movimento de construção da nova área de concentração, "Informação, mediações e cultura" também sinaliza uma forma específica de compreensão da ciência da informação, revalorizando sua dimensão como ciência social, portanto diretamente relacionada com perspectivas que incluem as dimensões históricas, culturais e contextuais de seus objetos de estudo (ARAÚJO, 2016).

É nesse sentido que a perspectiva de estudos sobre os sujeitos constitui uma contribuição específica para fazer avançar o conhecimento em ciência da informação: destacando o caráter ativo dos diferentes atores sociais, sua dimensão reflexiva, suas possibilidades de aceitar, recusar, reelaborar, interpretar e reinterpretar os conteúdos dos documentos e registros de conhecimento, intervir junto às instituições, serviços e unidades de informação. Estudar a informação pela perspectiva dos sujeitos é estar sempre atentos à própria constituição da realidade social, que só se realiza com a ação concreta dos sujeitos inseridos em seus contextos de atuação.

\section{Referências}

ALMEIDA JÚNIOR, O. F. de. Leitura, mediação e apropriação da informação. In: SANTOS, J. P. dos. (Org.). A leitura como prática pedagógica na formação do profissional da informação. Rio de Janeiro: Biblioteca Nacional, 2007. p. 33-45.

ALMEIDA JÚNIOR, O. F. de. Mediação da informação e múltiplas linguagens. Pesquisa Brasileira em Ciência da Informação, Brasília, v. 2, n. 1, p. 89-103, jan./dez. 2009.

ALONSO, L. F. C. A atividade de indexação: uma construção social da realidade. 2012. 94f. Dissertação (Mestrado em Ciência da Informação) Universidade Federal de Minas Gerais, Belo Horizonte, 2012.

ANTUNES, M. L. A. Comportamento informacional em tempos de Google. 2015. 206f. Dissertação. (Mestrado em Ciência da Informação) Universidade Federal de Minas Gerais, Belo Horizonte, 2015.

ARAÚJO, C. A. Á. Paradigma social nos estudos de usuários da informação: abordagem interacionista. Informação \& Sociedade: Estudos, João Pessoa, v. 22, n. 1, p. 145-159, jan./abr. 2012. 
ARAújo, C. A. Á. A perspectiva de estudos sobre os sujeitos na Arquivologia, na Biblioteconomia e na Museologia. Em Questão, Porto Alegre, v. 19, p. 213-238, 2013.

ARAÚJO, C. A. Á. Novo quadro conceitual para a ciência da informação: informação, mediações e cultura. Tendências da Pesquisa Brasileira em Ciência da Informação, João Pessoa, v. 9, p. 1-18, 2016.

ARAÚJO, C. A. Á. O que são 'práticas informacionais'? Informação em Pauta, Fortaleza, v. 2, p. 217-236, 2017.

ARAúJO, E. P. O. Tomada de decisão organizacional e subjetividade: análise das dimensões simbólico-afetivas no uso da informação em processos decisórios. 2013. 165f. Dissertação (Mestrado em Ciência da Informação) - Universidade Federal de Minas Gerais, Belo Horizonte, 2013.

BARROS, F. M. M. Protagonismo nas práticas informacionais de mães de crianças alérgicas. 2016. 186f. Dissertação (Mestrado em Ciência da Informação) - Universidade Federal de Minas Gerais, Belo Horizonte, 2016.

BOURDIEU, P. Razões práticas: sobre a teoria da ação. Campinas: Papirus, 1996.

CHAUÍ, M. O que é ideologia. São Paulo: Brasiliense, 1984.

COELHO DE SÁ, R. M. Compartilhamento do conhecimento e o processo de orientação de discentes de pós-graduação stricto sensu. 2015. $158 \mathrm{f}$. Dissertação (Mestrado em Ciência da Informação) - Universidade Federal de Minas Gerais, Belo Horizonte, 2015.

DERVIN, B.; NILAN, M. Information needs and uses. In: WILLIAMS, M. E. (ed). Annual Review of Information Science and Technology. Chicago, IL: Knowledge Industry Publications, 1986. v. 21, p. 3-33.

DUMONT, L. M. M. Leitura e competência informacional: interseções e interlocuções. In: ENCONTRO NACIONAL DE PESQUISA EM CIÊNCIA DA INFORMAÇÃO, 18., Marília, SP, 2017. Anais... Marília, UNESP, 2017. Disponível em: $<$ http://www.brapci.inf.br/index.php/article/download/59059>. Acesso em: 18 abr. 3018.

DUMONT, L. M. M.; PINHEIRO, E. G. Incursões teórico-metodológicas da etnometodologia na Ciência da Informação: aplicações em pesquisas sobre leitura. Informação \& Sociedade, João Pessoa, v. 25, p. 49-61, 2015. Disponível em: <file:///C:/Users/Ligia/Downloads/22773-58088-1PB.pdf>. Acesso em: 18 abr. 2018.

ESPIRITO SANTO, P. O que informam as cartas de leitores e leitoras enviadas a jornais impressos: os casos do Estado de Minas e do Le Monde. 2012. 314f. Tese (Doutorado em Ciência da Informação) - Universidade Federal de Minas Gerais, Belo Horizonte, Brasil. 2012. 
FÉLIX, A. F. Práticas educativas em bibliotecas escolares: a perspectiva da cultura escolar uma análise de múltiplos casos na RME/BH. 2014. $124 \mathrm{f}$. Dissertação (Mestrado em Ciência da Informação) - Universidade Federal de Minas Gerais, Belo Horizonte, 2014.

GANDRA, T. K. Inclusão digital na terceira idade: um estudo de usuários sob a perspectiva fenomenológica. 2012. 137f. Dissertação (Mestrado em Ciência da Informação) - Universidade Federal de Minas Gerais, Belo Horizonte, 2012.

GANDRA, T. K. Práticas informacionais dos visitantes do Museu Itinerante Ponto UFMG. 2017. 190f. Tese (Doutorado em Ciência da Informação) Universidade Federal de Minas Gerais, Belo Horizonte, 2017.

GOMES, M. A. Da educação de usuários à construção de competência em informação no contexto das bibliotecas das universidades federais: um estudo a partir da Universidade Federal de Alagoas e Universidade Federal de Minas Gerais. 2016. 324f. Tese (Doutorado em Ciência da Informação) - Universidade Federal de Minas Gerais, Belo Horizonte, Brasil. 2016.

LINE, M. B. Draft definitions: information and library needs, wants, demands and uses. Aslib Proceedings, Bingley, Reino Unido, v. 26, n. 2, p. 87, Feb. 1974.

LLOYD, A. Framing information literacy as information practice: site ontology and practice theory. Journal of Documentation, v. 66, n. 2, p. 245-258, 2010.

McKENZIE, P. A model of information practices in accounts of everyday-life information seeking. Journal of Documentation, v. 59, n. 1, p. 19-40, 2003. Disponível em: <http://publish.uwo.ca/ pmckenzi/McKenzie_J.Doc_2003.pdf>. Acesso em: 20 ago. 2017.

MOREIRA, J. Práticas educativas bibliotecárias de formação de leitores: um mapeamento de suas iniciativas e articulações na Rede Municipal de Ensino de Belo Horizonte RME- BH. 2014. 123f. Dissertação (Mestrado em Ciência da Informação) - Universidade Federal de Minas Gerais, Belo Horizonte, 2014.

PAIVA, R. M. V. A biblioteca escolar e os nativos digitais. 2018. Tese (Doutorado em Ciência da Informação) - Universidade Federal de Minas Gerais, Belo Horizonte, 2018.

PEREIRA, G. A colaboração no contexto da função educativa do bibliotecário. 2016. 142f. Tese (Doutorado em Ciência da Informação) Universidade Federal de Minas Gerais, Belo Horizonte, 2016.

PESSOA, M. T. A relação entre ouvintes assíduos e o rádio: um estudo de usuários da informação a partir de uma perspectiva compreensiva. 2010. 95f. Dissertação (Mestrado em Ciência da Informação) - Universidade Federal de Minas Gerais, Belo Horizonte, 2010. 
PINTO, F. V. de M. Práticas informacionais na organização político-sindical dos professores da rede municipal de Belo Horizonte. 2012. $155 f$. Dissertação (Mestrado em Ciência da Informação) - Universidade Federal de Minas Gerais, Belo Horizonte, 2012.

RAMOS, R. B. T. Com grandes poderes vêm grandes responsabilidades: um estudo etnometodológico sobre o leitor e a leitura de histórias em quadrinhos de super-heróis da Marvel e da DC Comics. 2017. 252f. Tese (Doutorado em Ciência da Informação) - Universidade Federal de Minas Gerais, Belo Horizonte, Brasil.

ROCHA, J. A. P. (In) Acessibilidade na web para pessoas com deficiência visual: um estudo de usuários à luz da Cognição situada. 2013. $160 f$. Dissertação (Mestrado em Ciência da Informação) - Universidade Federal de Minas Gerais, Belo Horizonte, 2013.

ROCHA, J. A. P.; SIRIHAL DUARTE, A. B.; PAULA, C. P. A. de. Modelos de práticas informacionais. Em Questão, Porto Alegre, n. 1, v.23, p.36-61, jan./abr. 2017.

SAVOLAINEN, R. Information behavior and information practice: reviewing the "umbrella concepts" of information-seeking studies. Library Quarterly, Chicago, v. 77, n. 2, p. 109-132, 2007.

SEPÚLVEDA, M. I. M. A relação dos bibliotecários com a profissão, com a rotina profissional e com os usuários a partir de uma perspectiva compreensiva. 2012. 120f. Dissertação (Mestrado em Ciência da Informação) - Universidade Federal de Minas Gerais, Belo Horizonte, 2012.

SILVA, R. A. da. As práticas informacionais das Profissionais do Sexo da zona boêmia de Belo Horizonte. 2008. 171f. Dissertação (Mestrado em Ciência da Informação) - Universidade Federal de Minas Gerais, Belo Horizonte, 2008.

SIRIHAL DUARTE, A. B.; ARAÚJO, C. A. A.; PAULA, C. P. A. de. Práticas Informacionais: desafios teóricos e empíricos de pesquisa. Informação em Pauta, Fortaleza, v. 2, núm. esp., p. 111-135, out. 2017.

TALJA, S.; HANSEN, P. Information Sharing. In: SPINK, A.; COLE, C. (Ed.). New directions in human information behavior. Berlin: Springer, 2005. p. 113-134.

TERTO, Ana Luísa de Vasconcelos. A extensão universitária e o Sistema de Informação da Extensão (SIEX/UFMG): um estudo de usuários a partir de uma perspectiva compreensiva. 2013. 107 f. Dissertação. (Mestrado em Ciência da Informação) - Universidade Federal de Minas Gerais, Belo Horizonte, 2013.

VASCONCELOS, P. M. As práticas informacionais das clientes dos serviços de estética. 2016. 79f. Dissertação (Mestrado em Ciência da Informação) - Universidade Federal de Minas Gerais, Belo Horizonte, 2016. 
VAZ, G. A. A importância dos estudos de usuários na formação do arquivista. 2015. 134f. Dissertação (Mestrado em Ciência da Informação) - Universidade Federal de Minas Gerais, Belo Horizonte, 2015.

WACQUANT, L. H. In: CATANI, A. et al. (Orgs.). Vocabulário Bourdieu. Belo Horizonte: Autêntica, 2017. p. 213-217. 